\title{
Cognitive distortions in the ideas of the person about his physical self: standardization of the method
}

\author{
Angelika Luchinkina ${ }^{*}$, Vladimir Senchenko ${ }^{1}$, Aizhan Dayrabaeva ${ }^{2}$ \\ ${ }^{1}$ Crimean Engineering and Pedagogical University, 295015 Simferopol, Russia \\ 2 Turan University, Economic Faculty, Nur-Sultan, Kazakhstan
}

\begin{abstract}
Based on the theory of A. Beck, the authors developed a research questionnaire "Cognitive distortions in the ideas of the person about his physical self-image". The questionnaire includes 20 questions with answer options, which are combined into ten blocks according to cognitive distortions according to A. Beck's model: Dichotomous thinking, Catastrophization, Depreciation of the positive, Emotional justification, Labeling, Mental filter, Reading of thoughts, Personalization, Commitment, Overgeneralization. Testing of the questionnaire was carried out on 400 respondents. Standardization took place in several stages: calculating the reliability of the questionnaire; calculation of the validity of the questionnaire. The results of standardization have confirmed that the author's questionnaire "Cognitive distortions in the ideas of the person about his physical self-image" successfully fulfills his goal: to study the severity of cognitive distortions of thinking. In the study of respondents with different combinations of gender, biological gender and level of Internet activity, leading cognitive distortions were identified that underlie the formation of a physical image of a person.
\end{abstract}

\section{Relevance}

The modern stage of personality development, the transfer of activity to virtual space, the creation of simulacra of the human body lead to the secondary nature of physicality. Adolescents and young people, those for whom the physical self-image in real space becomes more significant than other components of the self-image, experience a breakdown of ordinary attitudes, being in the Internet space and replacing the physical body with avatars and memes.

\footnotetext{
* Corresponding author: aluch@yandex.ru
} 
In the subjective picture of the world of the personality of the modern young man, a distorted image of the body, distorted cognitive attitudes towards his physical self-image can form, which is the cause of personality deviations and behavioral disorders. We assume that the cause of the incorrect perception of one's physical self is the cognitive mechanisms of thinking, which appear in the form of cognitive distortions.

\section{Statement of the primary material}

The greatest attention to the formation of cognitive attitudes is given in the works of A. Beck $[1,2]$. A. Beck writes that cognitive distortions of a person often mediate their relationship to their own bodies. It is worth noting that the person perceives the past, present and future of his own body through an established cognitive scheme. Following Beck, we highlight the following as the main cognitive distortions that influence the formation of attitude to the body: dichotomous thinking, catastrophization, depreciation of the positive, emotional justification, labeling, mental filter, reading thoughts, personalization, obligation, overrgeneration.

Examples of some cognitive distortion.

Reading thoughts: without certain facts or evidence, a person assumes that certain people will think about it. For example: they consider me ugly because I am fat; they consider me terrible because there is not enough weight in my body.

Catastrophization: a person suggests that if he receives a negative or insufficiently positive assessment of his body, appearance, it will be difficult to survive. For example: if they laugh at me, I will never be able to enter the audience again; I can't live a normal life if someone notices my extra weight.

Overgeneralization: a person, having a single but strong negative experience, builds his attitude to the world on the basis of it. Social psychologists and philologists (Myers D., Andreeva G.M., Goroshko E.I. and others) [3, 4, 5] write that such distortions are characteristic of victims of school bullying and bullying in children's groups. For example: once I was teased for the length of my legs, I'm sure it will be done again; I'm scared to get acquainted with the university group, because they, like my classmates, can laugh at my figure.

\section{Methods and results of the study}

Questionnaire I.S. Luchinkina aims to diagnose the cognitive distortions that underlie various communicative types [6]. To study the cognitive mechanisms of the formation of the image of physical self-image, we developed a research questionnaire "Cognitive distortions in the ideas of the person about his physical self-image".

At the stage of the ascertaining experiment, 60 respondents from each indicated group were selected using the random number method. Then, gender preferences in each group were investigated using the methodology of multilateral personality research MMPI (scale muscularity-femininity) and methodology S. Boehm "Muscularity-femininity". The choice of these methods is justified by their capabilities to most fully describe the gender characteristics of the respondents in the sample, both the clinical and socio-psychological picture. At the same stage, we analyzed the sexual and gender distribution of respondents among groups with different Internet activities.

Author's research questionnaire "Cognitive distortions in the ideas of the individual about his physical self-image". The questionnaire includes 20 questions with answer options, which are combined into ten blocks according to cognitive distortion by A. Beck's model. 
The presence of one or another cognitive one is determined by the sum of points received for the answers to the relevant questions [Table1].

Psychologists-practitioners with at least 5 years of experience and psycholinguists were involved in the examination of the questionnaire to assess the conformity of questions and answer options for each block of cognitive distortion.

During the assignment, each respondent in real space was provided with individual stimulus material, a separate place for diagnostic work.

Questionnaire "Cognitive distortions in the ideas of the person about his physical selfimage".

The purpose of the questionnaire is to study the severity of cognitive distortions of thinking.

Instruction. You are offered 20 questions with different answer options. Choose the most suitable answer from the five given in the table.

Table 1. An approximate part of the questionnaire form "Cognitive distortions in the ideas of the individual about his physical self-image".

\begin{tabular}{|c|l|c|c|c|c|c|}
\hline $\mathrm{n}$ & \multicolumn{1}{|c|}{ Statement } & $\begin{array}{c}\text { Totally } \\
\text { disagree }\end{array}$ & $\begin{array}{c}\text { I often } \\
\text { disagree } \\
1\end{array}$ & $\begin{array}{c}\text { I do not } \\
\text { care } \\
2\end{array}$ & $\begin{array}{c}\text { I agree more } \\
3\end{array}$ & $\begin{array}{c}\text { I } \\
\text { completely } \\
\text { agree } \\
4\end{array}$ \\
\hline 1 & Body must be perfect. & & & & & \\
\hline 2 & $\begin{array}{l}\text { It's terrible when you } \\
\text { realize you're not } \\
\text { handsome enough. }\end{array}$ & $\begin{array}{l}\text { Those who say that } \\
\text { appearance is not } \\
\text { important lie. }\end{array}$ & & & & \\
\hline
\end{tabular}

Block "Dichotomous thinking"

Statements:

No. 1 (1). Body must be perfect

No. 2 (11). A person who controls his body deserves respect.

In A. Beck's cognitive therapy, "dichotomous thinking" is an analogue of polar thinking of the black-and-white type with the absence of midtones. Experts noted that respondents with pronounced dichotomous thinking choose the extreme points of the scale beautiful-ugly, slim-fit, thin-fat.

Block "Catastrophization"

Statements:

No. 1 (2). It's terrible when you realize you're not handsome enough.

No. 2 (12). I'm upset if someone criticizes my appearance.

Cognitive distortion of the "catastrophic" type is associated with the respondent displaying negative emotions in connection with the events that occur, up to the inability to perform any actions. According to experts, respondents with a pronounced cognitive distortion of the catastrophic type fall into panic at the slightest deviations in the structure of the body, clothes from those set by society.

Block "Depreciation of the positive."

Statements:

No. 1 (3). Those who say that appearance is not important lie.

No. 2 (13). In beauty there is no merit of man himself.

The specified cognitive distortion of the type "devaluation of the positive" implies the devaluation of positive events and achievements [7]. For example: beautiful, but stupid. 
Block "Emotional justification". Statements:

No. 1 (4). A high forehead is a sign of the mind. No. 2 (14). The eyes are the mirror of the soul.

As a rule, an emotional justification is associated with confidence in the correctness of something, without any rational subtext. For example: the most beautiful women are blondehaired women; long hair, but the mind is short; everyone should brush their teeth.

Block "Labeling". Statements:

No. 1 (5) Women are dumber than men. No. 2 (15) Fat people are always stupid.

Respondents with such cognitive bias are prone to hasty conclusions, unrecognizable cliches.

Block "Mental filter". Statements:

No. 1 (6) People do not want to communicate with those who look bad. No. 2 (16) The ugly ones in life have more difficulties than beautiful ones.

Respondents with such cognitive bias, as a rule, select events with only the same color, ignoring others. For example: all fat people are offended in collectives; all stooped are losers.

Block "Reading Thoughts". Statements:

No. 1 (7) People always condemn fat and ugly. No. 2 (17) A person is always judged by his appearance.

Respondents with a high value on this scale are sure that they know what other people think and do not accept any rational evidence to the contrary [7]. For example: all people are disgusted to look at the fat.

Block "Personalization". Statements:

No. 1 (8) Man himself is to blame for his physical disabilities.

No. 2 (18) People are guilty of their own diseases.

Respondents with high scores on the personalization scale are looking for their own guilt and involvement in all problems.

Block "Commitment". Statements:

No. 1 (9) A person must be beautiful.

No. 2 (19) A person must lead a healthy lifestyle.

Respondents who have a pronounced cognitive bias "commitment" tend to limit emotional and behavioral reactions, use the verbs: obliged, must, so necessary [7].

Block "Overgeneralization". Statements:

No. 1 (10) All slim people have a good life.

No. 2 (20) Always greeted by clothes.

Respondents with "Overgeneralization" operate with extreme points of view and rigid assessments (either/or) [7]. Example: now there is a lot of food advertising, and as a result, all teens are fat.

We calculated the coefficient of linear correlation between the parts of the questionnaire.

Instrumental reliability was evaluated by expert psychologists with at least 5 years of experience and experience in the cognitive-behavioral paradigm. The stability of the characteristics of the questionnaire was checked by re-examination two months after the main one. The consistency of the questionnaire was studied by replacing the experimenter.

Table 2. Validity and reliability indicators of the author's research questionnaire.

\begin{tabular}{|c|c|c|c|c|c|c|c|}
\hline \multirow{2}{*}{ № } & \multirow{2}{*}{ Scale } & \multirow{2}{*}{$\begin{array}{c}\text { Validity } \\
\begin{array}{c}\text { exp } \\
\text { content }\end{array}\end{array}$} & \multicolumn{3}{|c|}{ Reliability } & $\begin{array}{c}\rho_{\text {theo }} \\
r\end{array}$ & $\begin{array}{c}\rho_{\text {theo }} \\
r\end{array}$ \\
\hline & & & $\begin{array}{c}\text { Instrument } \\
\text { al }\end{array}$ & $\begin{array}{c}\text { Con } \\
\text { stan } \\
\text { cy }\end{array}$ & $\begin{array}{c}\text { Stabil } \\
\text { ity }\end{array}$ & 0,86 & 0,82 \\
\hline
\end{tabular}




\begin{tabular}{|c|c|c|c|c|c|}
\hline 1 & $\begin{array}{l}\text { Dichotomous } \\
\text { thinking }\end{array}$ & 0,82 & 0,87 & 0,84 & 0,91 \\
\hline 2 & Catastrophization & 0,86 & 0,84 & 0,85 & 0,90 \\
\hline 3 & $\begin{array}{l}\text { Depreciation of the } \\
\text { positive }\end{array}$ & 0,79 & 0,96 & 0,91 & 0,97 \\
\hline 4 & $\begin{array}{l}\text { Emotional } \\
\text { justification }\end{array}$ & 0,86 & 0,86 & 0,91 & 0,97 \\
\hline 5 & Labeling & 0,87 & 0,83 & 0,94 & 0,89 \\
\hline 6 & Mental filter & 0,91 & 0,96 & 0,89 & 0,89 \\
\hline 7 & Reading of thoughts & 0,87 & 0,88 & 0,96 & 0,95 \\
\hline 8 & Personalization & 0,93 & 0,89 & 0,89 & 0,89 \\
\hline 9 & Commitment & 0,84 & 0,94 & 0,79 & 0,91 \\
\hline 10 & Overgeneralization & 0,89 & $0,9 \ddot{\mathrm{e}}$ & 0,91 & 0,91 \\
\hline
\end{tabular}

Content validity was determined by the opinion of experts. The Overgeneralization and Thought Filter scales were finalized, and then a check was carried out on a homogeneous sample of respondents As can be seen from table 2, $\rho_{\text {exp }}$ exceeds $\rho_{\text {theor }}$ (confidence levels of 0.05 and 0.01 ), which suggests the validity of the author's research questionnaire. The obtained coefficients of stability and constancy of the psycho-diagnostic tool also exceed $\rho_{\text {theor }}$, which indicates a high reliability of the questionnaire. Based on the distribution curve, we have identified reliable values for each of the scales. So, it was noted that the absence (or low severity) of cognitive distortion correlates with a value of 0-2 points; the presence of a tendency to cognitive distortion correlates with a value of 3-4 points; the presence of cognitive distortion correlates with a value of 5-8 points.

In addition, reliable results were obtained on a gender-uniform sample.

The study of cognitive distortions in groups of respondents that differ in gender and Internet activity allowed us to highlight the following results [Figure 1]. 


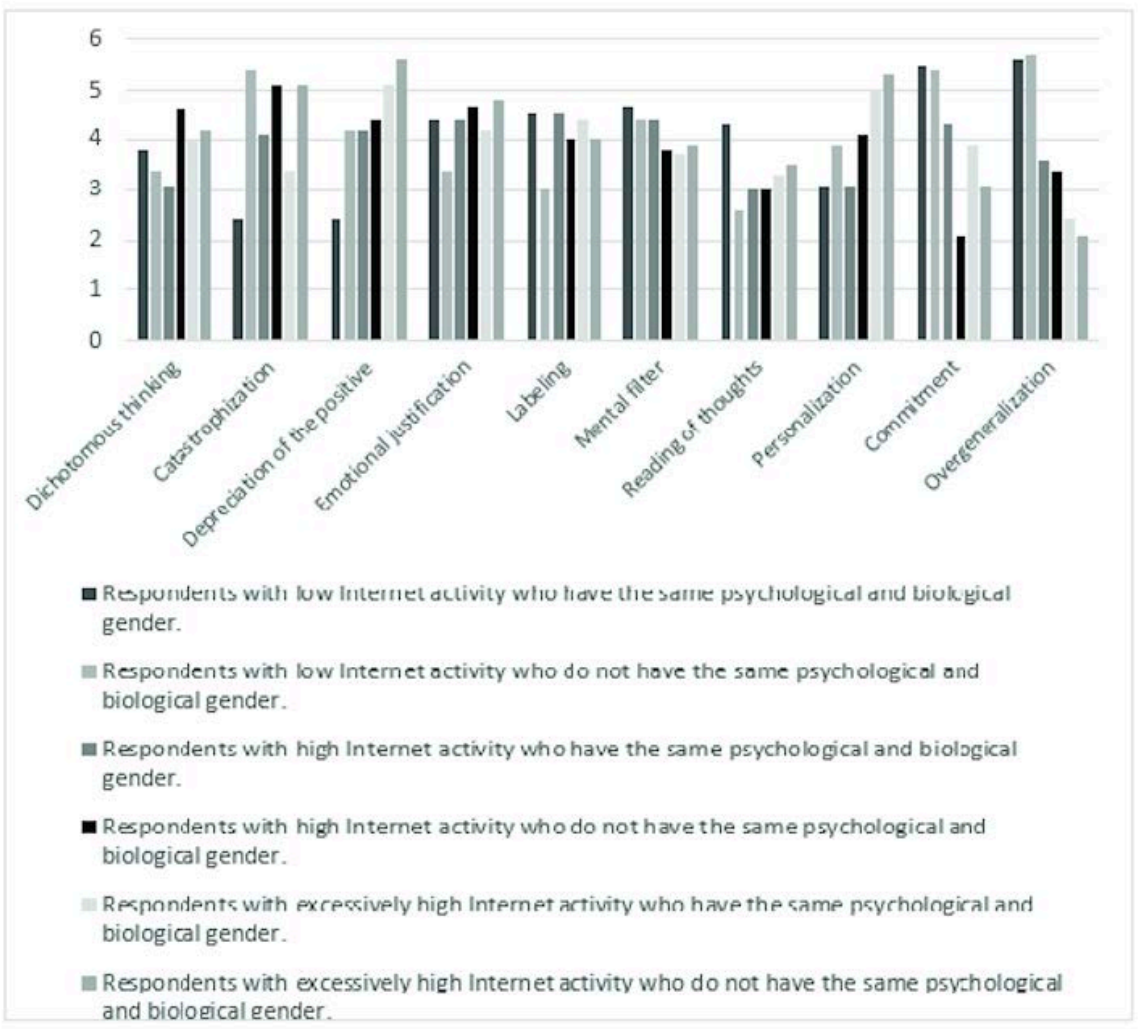

Fig. 1. Cognitive distortions of respondents of different gender and Internet activity groups (average values on scales)

As can be seen in Figure 1, respondents with low internet activity, who have the same psychological and biological sex, are dominated by obligation, overgeneralization, reading thoughts, a mental filter, dichotomous thinking, labeling. Scales of corresponding cognitive distortions are above average. For respondents with low internet activity, who do not have the same psychological and biological gender, catastrophization, obligation, and overgeneralization are the predominant cognitive distortions. Respondents with high internet activity who have the same psychological and biological sex have average scores on all scales. Respondents with low internet activity who do not have the same psychological and biological gender have higher than average scales. Respondents with excessively high internet activity, who have the same psychological and biological sex, have values higher than the average on the scales of dichotomous thinking, depreciation of the positive, catastrophization, personalization. Respondents with excessively high internet activity, who do not have the same psychological and biological sex, are characterized by high catastrophic values, depreciation of the positive and personalization.

\section{Conclusion}

Thus, the testing of the questionnaire was carried out on 400 respondents. The questionnaire is standardized. Standardization took place in several stages: calculating the reliability of the questionnaire; calculation of the validity of the questionnaire. We can state that the author's questionnaire "Cognitive distortions in the ideas of the person about his physical self-image" successfully fulfills his goal. A study conducted on groups of students with different gender 
and instrumental characteristics revealed differences in the choice of cognitive distortions in the formation of their physical self-image.

\section{References}

1. A.I. Luchinkina, Hum. Scien. 1, (2016)

2. A. Beck, Cognitive Psychotherapy for Personality Disorders (Piter, St. Petersburg, 2019)

3. D. Myers, Social Psychology (The McGraw-Hill Companies, New York, 2010)

4. G.M. Andreeva, Social Psychology (Aspect Press, Moscow, 2010)

5. E.I. Goroshko, Features of male and female verbal behavior (Institute of Linguistics, Moscow, 1996)

6. I.S. Luchinkina, Scien. Res. 4, (2018)

7. A. Beck, Cognitive Therapy for Depression (Piter, St. Petersburg, 2003) 